\title{
The crossword puzzle paradigm: The effectiveness of different word fragments as cues for the retrieval of words
}

\author{
NAOMI GOLDBLUM \\ The Hebrew University, Jerusalem, Israel
}

and

\author{
RAM FROST \\ The Hebrew University, Jerusalem, Israel \\ and Haskins Laboratories, New Haven, Connecticut
}

\begin{abstract}
We investigated the internal structure of words in the mental lexicon by using a crossword puzzle paradigm. In two experiments, subjects were presented with word fragments along with a semantic cue, and were asked to retrieve the whole word that contained the presented fragment and was compatible with the semantic information. In Experiment 1, we found that any cluster of three adjacent letters facilitated retrieval better than dispersed letters. Moreover, syllabic clusters had a greater facilitative effect than nonsyllabic pronounceable clusters or nonpronounceable clusters. In Experiment 2, we found that syllable units facilitated retrieval better than morphemic units. The results are interpreted as evidence for the existence of lexical subunits that are larger than the letter but smaller than the word, and that are organized according to phonologic principles. We propose an interactive model for how crossword puzzles are solved.
\end{abstract}

In this study we are concerned with the following questions: Does the mental lexicon contain units smaller than the whole word but larger than the individual letter, and, if so, what kind of units are they? Previous answers to these questions have been modality specific. There is wide agreement that syllabic units play an important role in auditory word perception (e.g., Kahn, 1976; Mehler, Dommergues, Frauenfelder, \& Segui, 1981; Segui, 1984). In research on visual word perception, on the other hand, there is conflicting evidence as to what the subword units might be, and whether or not the visually presented stimuli undergo phonologic as well as visual processing. Spoehr and Smith (1975) showed that a vocalic center group (VCG) is more easily perceived than a similar cluster of letters not containing a vowel. Their use of the VCG is based on the work of Hansen and Rodgers (1965), who defined a VCG as a cluster consisting of a vowel with a consonant or consonants on either side, where the whole cluster forms a pronounceable unit. AN, CAN, ANT, and CANT are examples of VCGs. Spoehr and Smith (1973; see also Spoehr, 1978) also showed that one-syllable words are processed faster and more accurately than two-

The authors wish to thank Len Katz, Bruno Repp, Laurie Feldman, Susan Brady, Catherine Browman, Benny Shanon, Itzhak Schlesinger, and two anonymous reviewers for useful comments on earlier drafts of this paper. This work was supported in part by National Institute of Child Health and Human Development Grant HD-09144 to Haskins Laboratories. The study is based on a master's thesis presented by the first author to the Department of Psychology at The Hebrew University. Correspondence should be addressed to Ram Frost, Haskins Laboratories, 270 Crown Street, New Haven, CT 06511. syllable words with the same number of letters. From these results Spoehr and Smith concluded that words are represented in the lexicon according to their syllabic structure.

In contrast to the phonological division suggested by Spoehr and Smith, Murrell and Morton (1974) and Taft and Forster (1975) proposed a morphological division into units. According to this view, polymorphemic words are stored in the lexicon in morphologically decomposed units: the root and the information about prefixes and inflections. Thus, in the process of word recognition, the reader strips the prefixes and accesses the morphological root first. A different division of written words into units was suggested by Taft (1979). Taft defined the minimal lexical unit as the Basic Orthographic Syllabic Structure (BOSS). The BOSS is formed by adding to the first vowel in the first syllable as many consonants as possible without violating the orthotactic rules of English. Thus, the BOSS is a unit consisting of as many consonants as can legally be found together with one vowel, at the beginning of a word. According to this view, in order to access a multimorphemic word in the mental lexicon, one first accesses its BOSS unit. In a series of experiments designed to investigate Taft's hypothesis, Lima and Pollatsek (1983) found no difference between the facilitative effect of syllables and that of BOSS units. They demonstrated, however, that either of these units was better than an arbitrary unit in priming a word of which the unit was a constituent. When a syllabic unit was also a morphemic unit of the word, it was more facilitative than a syllabic unit that did not constitute a morpheme of the word. 
This inconsistency of results is puzzling but may perhaps be attributed to task characteristics. All of the studies cited above concerned visual word perception, and most of them used the lexical decision paradigm. Usually, in such experiments, words that are parsed into units according to phonologic or orthographic principles are visually presented to the subject. Here, the speed and accuracy of lexical decisions to such parsed words is assumed to reflect the naturalness of these units. It is assumed that if lexical search is facilitated by a particular division of a word, this division actually reflects important characteristics of the representation of this word in the internal lexicon. However, it has recently been suggested that lexical decisions, in many cases, do not involve more than superficial lexical access (Balota \& Chumbley, 1984). Since all that is needed for lexical decision is a decision concerning the probability that the letter string is a valid word, it is possible that, for at least some words, the decision is based on a fast judgment concerning the familiarity of the letter string. In such cases, the decision stage occurs prior to any deep analysis of meaning and morphemic structure. This suggestion is described in a two-stage model of lexical decision performance (Balota \& Chumbley, 1984). According to this model, very familiar and very unfamiliar letter strings are processed superficially without lexical access. Only when a fast decision concerning their familiarity cannot be reached does the letter string undergo deeper processing that involves decomposition into units. Consequently, in a lexical decision task, in which a whole word is presented to the subject, a division of the word into subunits may be irrelevant to the task. If this is the case, then the structure of the internal lexicon may not be accurately reflected by performance in lexical decision experiments.

A retrieval task, on the other hand, can avoid the artifacts of the lexical decision process. If only a fragment of a word is presented, and the subject is asked to retrieve the whole word containing this fragment, the extent to which a particular fragment facilitates retrieval may reflect the functional role of this fragment in the lexicon.

An example of such cue-facilitated retrieval is the process that occurs in the solving of crossword puzzles. When part of the word is filled in, the solver has two cues for the retrieval of the word: the filled-in letters in their appropriate places and the definition, which is generally a synonym or some other associative term. When the solver cannot come up with the correct answer, he/she tries to fill in more letters by finding adjacent words. The solver usually chooses the position to be filled next, according to his/her intuition about the relative facilitatory effect of the positions that are still empty. This raises the following questions: What facilitates retrieval better, dispersed letters or letter clusters? Also, are there any differences among types of clusters? The study of the relative facilitatory effect of different types of word fragments may provide us, then, with useful clues about the structural representation of words in the mental lexicon. If words in the internal lexicon are actually organized in terms of subunits, it is more likely that people will make use of these subunits when they are presented with them and asked to retrieve the whole word, rather than simply making lexical decisions.

A number of experiments using the word-fragment paradigm indicate that with the number of letters controlled, all fragments are not equally effective for the retrieval of words. Horowitz, White, and Atwood (1968) presented subjects with lists of nine-letter words to memorize, and then tested whether the first, middle, or last three-letter fragment best facilitated recall. They found that the first fragment was most facilitative, followed by the last, with the middle fragment worst. However, Horowitz and his colleagues did not control the pronounceability of the fragments or whether they corresponded to syllables. This factor might have had some influence on the results. Since the middle fragment of a nine-letter word is less likely to be pronounceable than either of the end fragments, the position of the fragment may have been confounded with its pronounceability. Using a similar procedure, Dolinsky (1973) repeated this experiment with a control for the presence of syllables. After his subjects were presented with a list of words, recall was cued by presentation of syllabic and nonsyllabic fragments from the beginning, middle, or end of each word. Dolinsky found that the presence of a syllable had a significant facilitative effect on retrieval only in the middle fragments. When the cues were the beginning or final fragments, syllabic clusters did not facilitate recall better than nonsyllabic clusters. However, Dolinsky did not control for the pronounceability of the nonsyllable fragments and some of his nonsyllable controls were actually three letters of a four-letter syllable.

In the present study, the word-fragment technique was used to investigate what sublexical word units, if any, exist in the internal lexicon, with the letters' position controlled. The possibilities were (1) that individual letters in a word act separately and in parallel to activate directly the word of which they are constituents, (2) that any group of consecutive letters in a word constitutes a unit, or (3) that only very specific groups of consecutive letters have an activating effect greater than that of individual dispersed letters. If there are no middle-sized units in the lexicon, then all fragments of the same length should be equally helpful in retrieving a word. If letters grouped together are more effective in activating a word, then any group of consecutive letters should be a better retrieval cue than the same number of dispersed letters. If, however, there are specific groupings of letters that constitute units in the internal lexicon (e.g., syllables), then these specific groupings should be more effective cues for word retrieval than any other groupings of the same length.

\section{EXPERIMENT 1}

Experiment 1 was designed to investigate whether letter clusters facilitate retrieval more than dispersed letters, 
and whether syllabic units are more facilitative than any other cluster of letters, independently of their position in the word. To this end, syllabic units were compared with three types of fragments: pronounceable nonsyllabic clusters, unpronounceable clusters, and nonadjacent letters. To avoid the effect of length of cluster, all word fragments were composed of different combinations of three letters. For example, the target word VINDICTIVE was cued by the synonym spiteful, together with one of the following four fragments:

$$
\begin{aligned}
& \text { 1. -__DIC _-_-- (syllable) } \\
& \text { 2. ___ICT } \\
& \text { 3. -_NDI _-_- (unpronounceable cluster) } \\
& \text { 4. _-_N_I_T _-_ (nonadjacent letters). }
\end{aligned}
$$

If there are no units larger than the individual letter in the internal lexicon, then any three letters of a word should be just as good a retrieval cue as any other three letters situated in similar positions within the word. If it is the clustering of the letters in itself that facilitates retrieval, then any cluster should be better than dispersed letters, with no differences among clusters of different types. If it is merely the pronounceability of the cluster that facilitates retrieval, then pronounceable clusters should be as facilitative as true syllables. If, however, syllables do constitute functional units in the internal lexicon, then a syllable should be more facilitative for the retrieval of the target word than any of the other fragments.

\section{Method}

Subjects. Sixty-four undergraduate students at The Hebrew University of Jerusalem participated in the experiment for course credit or for payment. All subjects were native English speakers.

Stimuli and Design. The stimuli were 48 English words: 22 nouns, 8 verbs, and 18 adjectives. All the words had three syllables and were from 7 to 10 letters long. Their frequency, according to Kucera and Francis (1967), ranged from 0 to 45, with a median of 10.5. There were no significant differences among the frequencies of the fragments of each type of cluster, according to the trigram frequency list presented by Underwood and Schulz (1960).

Four different types of fragments were presented for each word: a syllable, a pronounceable cluster that was not a syllable of this word, an unpronounceable cluster, and three nonadjacent letters. ${ }^{1}$ Syllables were defined according to Webster's New World Dictionary of the American Language (1964). In those cases where the dictionary proposed two divisions, phonologic and orthographic, the phonologic division was used. All fragment types consisted of three letters; dashes were presented in place of all the missing letters. To eliminate the possibility that the number of vowels or consonants in the fragment might have some effect on retrieval, only fragments consisting of two consonants and one vowel were used. In order to ensure that the effect of the type of fragment was not confounded with the effect of the fragment's position, all the possible positions within the word were sampled. For the syllabic fragments, the first, middle, and last syllables were presented equally often. In the isolated-letters condition, half of the trials included either the first or the last letters of the word, and the remaining trials did not. The unpronounceable fragments were always in the middle of the word, as there are no words in which the first and the last fragments are unpronounceable, given the constraint that the fragment must contain a vowel. A semantic cue for the word, that is, a word or a phrase with approximately the same meaning as the target word, was presented in lowercase letters just above the configuration of letters and dashes.

Each word was presented with all four types of fragments, so as to serve as its own control. The subjects were divided into four groups. Each group was presented with only one of the four fragments of each word, in one of the possible fragment positions. Each group was presented with an equal number of words in each of the four fragment conditions. The different words in the different conditions were assigned to the four groups of subjects by means of a Latin square design, so that no subject saw a word more than once. The list of target words and fragments is presented in the Appendix.

Procedure and Apparatus. The subjects were seated approximately $70 \mathrm{~cm}$ from a CRT screen in a semidarkened room. Each stimulus appeared on the screen after the subject pressed a "start" button. The experimenter pressed a "finish" button when the correct answer was given by the subject, and only then was the stimulus removed from the screen. This procedure was deemed necessary because subjects often made incorrect spontaneous vocal responses. Consequently, a voice key for determining the exact reaction time (RT) could not have been used. However, in order to avoid an experimenter bias, the experimenter did not face the screen and was not aware of the specific fragment condition in each trial. Rather, the experimenter was presented with a parallel list that contained all the correct responses, and pressed the "finish" button accordingly. If the subject gave an incorrect answer, he/she was told that it was incorrect and was allowed to guess again. If, however, the subject did not give the correct response in $30 \mathrm{sec}$, the stimulus disappeared, RT was recorded as $30 \mathrm{sec}$, and the trial was considered a "no response" trial. Stimulus presentations and RT measurements were controlled by a PDP 11/23 computer. The subjects were presented with three practice trials before the test stimuli were presented.

\section{Results and Discussion}

RTs and "no response" rates were calculated and averaged for the four experimental groups across the four fragment conditions. They are presented in Table 1 . The mean RTs for each type of fragment were calculated across the different positions within the word. A one-way analysis of variance (ANOVA) revealed that the differences among the mean RTs to the different fragment types were significant $\left[F_{1}(3,189)=83.5, p<.001\right.$ and $F_{2}(3,141)=$ $\left.29.5, p<.001 ; \min F^{\prime}=21.8, p<.05\right]$.

Planned comparisons were performed only between those groups of words in each condition for which the fragment clusters were at comparable positions within the words. Thus, the results were based strictly on the effect of the fragment type without being confounded with position effects. The results of the planned comparisons are presented in Table 2 . The results clearly demonstrate that the syllabic fragments were better retrieval cues than any other fragment in a given position in a word. It is of interest to note that there was no significant difference between the two kinds of nonsyllabic clusters, the pronounceable nonsyllable and the unpronounceable cluster. However, it is clear that clustering in itself facilitates retrieval, inasmuch as any cluster yielded better performance than did nonadjacent letters.

In considering the facilitation of syllabic fragments versus pronounceable nonsyllabic fragments, one cannot 
Table 1

Mean Reaction Time (RT, in sec), Percentage of "No Response," and Standard Deviations in the Four Fragment Conditions

\begin{tabular}{|c|c|c|c|c|}
\hline \multirow[b]{2}{*}{ Condition } & \multicolumn{2}{|c|}{ RT } & \multicolumn{2}{|c|}{ Percent "No Response" } \\
\hline & $M$ & $S D$ & $M$ & $S D$ \\
\hline Syllable & 11.6 & 4.2 & 24.7 & 15.2 \\
\hline Pronounceable & & & & \\
\hline Nonsyllable & 16.4 & 4.7 & 40.1 & 18.4 \\
\hline Unpronounceable & & & & \\
\hline Cluster & 19.0 & 4.1 & 50.9 & 15.5 \\
\hline Nonadjacent & & & & \\
\hline Letters & 20.9 & 3.6 & 54.9 & 16.0 \\
\hline
\end{tabular}

disregard the fact that for many words the division into syllables is controversial. Although in English some words have clear syllabic boundaries (e.g., after), for many words the syllabic boundaries are not well defined (e.g., dagger). These words contain ambisyllabic segments in most cases, in which a clear and unequivocal break does not exist. Ambisyllabicity is the major reason there is more than one theory of syllabification in English, because different parsings into syllables can be suggested for many words (see Kahn, 1976).

Ambiguous syllabification is not only a linguistic issue, but also a psychological and methodological one. Some of the controversy that revolves around the effect of syllables in word perception may be due to the use of stimuli whose syllabification is ambiguous. The use of such stimuli might have prevented previous researchers from finding a clear facilitation for syllabic units. In the present study, however, we found a strong facilitation of syllabic clusters even though a great many of the experimental stimuli contained ambisyllabic segments. We believe that even greater facilitation could be demonstrated in a study using only words with unequivocal syllabic boundaries.

Unambiguous syllabifications can be easily differentiated from ambiguous ones. Although linguists disagree about the correct syllabic boundaries of many words, there is a set of syllabification rules that they do agree upon. For example, it is fairly well accepted that a syllable must begin and end with consonants or sequences of consonants that are legal in word-initial and word-final position, that adjacent vowels belong to different syllables, and that the stressed syllable in a word will contain the maximum permissible number of consonants.

Because of the great theoretical relevance of ambiguous syllabification, we examined the results separately for words with unambiguous syllabification. The differences between syllabic and nonsyllabic pronounceable clusters only increased: RT $=9.6(S D=5.5)$ and RT $=14.9$ $(S D=9.2)$ for syllabic and nonsyllabic fragments, respectively. The results for percentages of "no response" were similar: $16.2 \%$ for syllables and $36 \%$ for nonsyllabic fragments.

\section{EXPERIMENT 2}

The results of Experiment 1 showed that syllables facilitated retrieval of words from semantic memory. However, it is not clear whether the facilitation that was found for syllabic units should be attributed to phonology or to mor-

Table 2

Planned Comparisons of Reaction Times (RTs) Between Pairs of Fragment Conditions, With Subject Random (SR) and With Word Random (WR)

\begin{tabular}{|c|c|c|c|c|c|c|c|}
\hline \multirow{2}{*}{$\begin{array}{l}\text { Conditions } \\
\text { Compared }\end{array}$} & \multicolumn{2}{|c|}{ Percent "No Response" } & \multicolumn{2}{|c|}{ RT (sec) } & \multirow{2}{*}{\multicolumn{3}{|c|}{$t$ value }} \\
\hline & $M$ & $S D$ & $M$ & $S D$ & & & \\
\hline $\begin{array}{l}\text { Syllable } \\
\text { Pronounceable }\end{array}$ & 22.4 & 16.4 & 11.2 & 4.5 & SR & $t(63)=$ & $=5.16, p<.001$ \\
\hline Nonsyllable & 37.5 & 20.7 & 15.5 & 5.2 & WR & $t(35)$ & $=2.53, p<.02$ \\
\hline $\begin{array}{l}\text { Pronounceable } \\
\text { Nonsyllable } \\
\text { Unpronounceable }\end{array}$ & 48.4 & 21.0 & 18.6 & 5.2 & SR & $t(63)$ & $=0.89$, n.s. \\
\hline Cluster & 44.8 & 17.3 & 17.9 & 4.7 & WR & $t(35)$ & $=0.80$, n.s. \\
\hline $\begin{array}{l}\text { Pronounceable } \\
\text { Nonsyllable } \\
\text { Nonadjacent }\end{array}$ & 37.1 & 20.7 & 15.5 & 5.2 & SR & $t(63)=$ & $=8.08, p<.001$ \\
\hline Letters & 55.6 & 17.7 & 21.0 & 4.1 & WR & $t(35)$ & $=3.80, p<.001$ \\
\hline $\begin{array}{l}\text { Unprounceable } \\
\text { Cluster } \\
\text { Nonadjacent }\end{array}$ & 55.5 & 22.2 & 20.6 & 5.2 & SR & $t(63)$ & $=2.72, p<.008$ \\
\hline Letters & 64.8 & 22.5 & 23.0 & 5.0 & WR & $t(23)$ & $=2.38, p<.026$ \\
\hline
\end{tabular}


phology. Experiment 2 was designed to address this issue by investigating the facilitative effects of phonologic units versus morphemic units.

Chomsky and Halle (1968) suggested that morphemes, rather than phonologic units, are stored in lexical memory in English. This suggestion is based on the claim that the syllabic structure of a word changes in a systematic way when affixes are added to it, while the underlying morphemic structure remains the same. Thus, it is more parsimonious to store the morphemic structure together with the rules for generating the phonologic structure according to the affixes added to the basic word.

Reading research provides additional evidence supporting the existence of morphemic units. Marcel (1980) suggested that in the process of reading, the reader parses the letter string not only by a cumulative exhaustive procedure, but also according to morphemic specifications that are in the visual lexicon. Kay and Marcel (1981) presented subjects with nonwords containing legal morphemes and demonstrated that naming latencies depended on the pronunciation regularity of the morphemes. Kay and Marcel therefore suggested that morphemic units are probably the basis on which beginning readers generate phonology.

A different technique for investigating lexical units was suggested by Prinzmetal, Treiman, and Rho (1986), who presented subjects with a target letter followed briefly by a string of colored letters. Prinzmetal et al. demonstrated that subjects sometimes report seeing letters and colors in incorrect combinations (illusory conjunction). Hence, they investigated in what type of letter combinations these illusory conjunctions were more likely to occur. Their results suggested that syllables defined by purely phonological principles did not affect feature integration. Contrarily, syllables that were defined by morphological boundaries were functional units in the visual analysis.

However, morphemic and syllabic units tend to overlap to a great extent. In most English words the morphemic units either are identical with the syllabic units or have one more letter at the end. This overlapping of units may be one of the reasons for the difficulty in obtaining clear-cut results concerning their effects. Therefore, to test this, in Experiment 2 we employed stimuli containing morphemic and syllabic units that do not overlap.

\section{Method}

Subjects. Forty-eight undergraduate students from The Hebrew University, all native English speakers, participated in the experiment for course credit or for payment.

Stimuli and Design. The stimuli were 24 English words: 7 nouns, 4 verbs, and 13 adjectives. Twenty-one of the words had four syl- lables, and the remaining three had five. The words were 7 to 12 letters long. Their frequencies, according to Kucera and Francis (1967), ranged from 0 to 43 , with a median of 7 . All the words were of Greek or Latin origin, and their decomposition into morphemes was defined according to Aronoff (1976). In order to avoid a confounding with the fragment position within the word, only the middle fragments were used as cues. Each word contained a middle morphemic unit and a middle syllabic unit that was not contained within the morphemic unit. Words of this type are not pronounced according to their morphemic structure. For example, the morphemes of the word monotonous are mono, ton, and ous, whereas the stressed syllable (which was the phonetic unit used in every case) is not. We could therefore compare the effects of _._NOT _._._ and _._._TON _._. as cues, together with the semantic synonym boring; dull. Each synonym was presented with a morphemic fragment to one group of subjects and with a syllabic fragment to another group of subjects. Altogether, the subjects in each group saw each word only once. They were presented with half of the syllabic fragments and half of the morphemic fragments, randomly selected. The procedure and apparatus were identical to those in Experiment 1. The list of target words is presented in the Appendix.

\section{Results and Discussion}

Mean RTs and the percentage of "no response" for words cued by morphemic fragments and words cued by phonetic fragments are presented in Table 3 . The differences in RTs were significant with subjects as the random variable and with words as the random variable [t(47) $=5.23, p<.001$, and $t(23)=1.92, p<.065$, respectively].

Experiment 2 thus showed that for the words used in the present study, syllabic units were more facilitative for the retrieval of words than were morphemic units. These results apparently conflict with the results of experiments that employed lexical decision and naming tasks and yielded better performance for words that were parsed according to morphemic principles (e.g., Murrell \& Morton, 1974; Taft, 1979). This discrepancy in results deserves attention.

The comparison of morphemic and syllabic units in English is methodologically problematic, as the results are heavily dependent on the choice of units in each experiment. The morphemic units that were used by Taft (1979) and Murrell and Morton (1974) often consisted of independent lexical units (i.e., ordinary words of the language). Therefore, there is no question that these units are stored as such in the internal lexicon, and for these specific words it is reasonable to assume that the morphemic units convey more information than any other units.

The empirical question addressed in Experiment 2 refers to the comparison of morphemic and syllabic units that do not have an independent lexical status. However,

Table 3

Mean Reaction Time (RT, in sec), Percentage of "No Response," and Standard Deviations for Words Cued by Morphemic and Phonetic Fragments

\begin{tabular}{lccccc}
\hline & \multicolumn{2}{c}{ RT } & & \multicolumn{2}{c}{ Percent "No Response" } \\
\cline { 2 - 3 } \cline { 5 - 6 } Cue & $M$ & $S D$ & & $M$ & $S D$ \\
\hline Morphemic & 16.3 & 3.5 & & 40.1 & 14.0 \\
Phonetic & 13.3 & 4.2 & & 29.2 & 16.5 \\
\hline
\end{tabular}


as was previously pointed out, in most of these cases the syllabic and morphologic segmentations overlap. Hence, the only set of stimuli that allows a test of the relative facilitation of phonologic and morphemic units is one that does not confound syllables and morphemes. Unfortunately, such a set of words is usually composed of words of Greek or Latin origin, and the naive reader is usually unaware of the morphemes' meaning. The results of Experiment 2 clearly demonstrate that, at least for this type of word, morphemic units do not play an important role. These units are theoretical constructs used by linguists to explain the structures of English words. Our results suggest that people do not have a deep linguistic knowledge of their language. Units that do not have a phenomenological reality for the individual do not have a psychological reality.

In conclusion, although our results do not rule out the possibility that some morphemes might be better cues than others, they conflict with a strong version of morphemic lexical structure that claims that only morphemes are stored in the lexicon. The pattern of cue facilitation obtained in Experiment 2 suggests that phonologic units do play a role in the retrieval of words and that, all other things being equal, they are best cues for word retrieval. Since phonologic units have also been shown to play a role in the perception of both auditorily and visually presented words (e.g., Mehler et al., 1981, and Spoehr \& Smith, 1975, respectively), they are thus seen to be involved in many aspects of the internal processing of words.

\section{GENERAL DISCUSSION}

In the present study we investigated the nature of word units in the internal lexicon by using a crossword puzzle paradigm. Experiment 1 showed that any grouping of letters is more facilitative in retrieving words from memory than are dispersed letters. This result, however, is not surprising. It appears that the information afforded by a given set of clustered letters is more than the sum of the information afforded by each of the cluster's constituents alone. This conclusion is in accordance with McClelland and Rumelhart's (1981) model of word recognition. According to their model, the greater activation of three adjacent letters derives from the pattern of activation characteristic of any adjacent positions. The claim for the existence of units in the lexicon, however, does not refer just to the relative position of letters at the letter level, but to the existence of independent subunits above the letter level but below the word level.

The controversy resides in the definition of these units. The results of Experiments 1 and 2, taken together, demonstrate that phonologic units are more facilitative for the retrieval of words than are any other units. It is important to note that this effect cannot be attributed to pronounceability factors alone. In Experiment 1, there was no significant difference between the nonsyllabic pronounceable and unpronounceable clusters; moreover, the syllabic cluster facilitated retrieval more than either one of them.

In Experiment 2, we directly tested the relative facilitation caused by syllabic and morphemic units. Although we cannot rule out the possibility that morphemic units also play some role in the internal processing of words, we suggest that syllabic units are more central. Thus, we propose that syllabic units are stored as such in the lexicon.

A model based on this hypothesis can be constructed as an extension of the interactive model of the lexicon proposed by McClelland and Rumelhart (1981). Using similar principles, we, too, propose a model in which words are connected by excitatory links to the letters they comprise. However, we suggest that the word and letter nodes are mediated by a third level that is composed of letter units. These units reside between the word level and the letter level and are organized according to syllabic principles. According to this model, a word can be recognized or retrieved on the basis of the isolated letters contained in it. However, retrieval is facilitated if the intermediate syllabic units are activated by a previously presented cue. This is because the syllabic units are more closely related to the word level than are the dispersed letters. In the crossword puzzle task, when a syllabic configuration is presented to the solver, it directly activates the node in the lexical network that is consistent with the presented information. This node, however, only rarely activates a single word node, as usually more than one word contains one specific syllable. If the word cannot be retrieved, then the addition of semantic information may eliminate some of the possible word candidates and may cause greater activation in the remaining ones. The complete activation of a specific word in the network (i.e., the retrieval of that word) is aided, therefore, by the additional semantic cue. The semantic information that is given with the letter configuration activates in parallel, through top-down processes, those word nodes that are consistent with it. The combination of the unit's bottom-up activation and the semantic information's top-down activation finally enables the retrieval of the target word from the lexicon. By the same argument, the addition of any single letter to the letter configuration will also narrow the number of competing words, thus facilitating retrieval. If, however the added letter completes a syllabic unit, the increase in bottom-up activation will comprise two factors: the added activation of that specific letter, but also, and more importantly, the additional activation of the complete syllabic unit. Thus, the completion of a full syllabic unit increases the probability of word retrieval.

Note that although in the present experiments the stimuli were presented in the visual modality, by no means do we suggest that only the visual lexicon is involved in the process of word retrieval. Because the retrieval task requires relatively long reaction times, and may not tap online processing, it is reasonable to believe that both the auditory and the visual lexicons are involved in the task. In many cases the final activation of a word node (i.e., 
word retrieval) can derive from activation of either lexicon or both. Regardless of this possibility, we believe that the differences in the relative facilitation of the visually presented letter clusters reflect their relative lexical status.

In conclusion, we suggest that the word-fragment completion task is a sensitive task for investigating lexical structure. Results from this task suggest that subunits of words that are larger than the letter unit are probably stored in the mental lexicon along with the words themselves. These subunits and their interconnections make up the lexical word. As syllables appear to be the best cue for word retrieval, we suggest that syllabic units have a strong lexical reality. The exact formal definition of the syllabic units in many English words is the source of much disagreement among linguists. This question, however, might be regarded as an empirical and psychological question. Thus, the word-fragment completion task could provide empirical evidence that might influence current linguistic theories.

\section{REFERENCES}

ARonoff, M. (1976). Word formation in generative grammar. Cambridge, MA: MIT Press.

Balota, D. A., \& Chumbley, J. I. (1984). Are lexical decisions a good measure of lexical access? The role of word frequency in the neglected decision stage. Journal of Experimental Psychology: Human Perception \& Performance, 10, 340-357.

Chомsкy, N., \& Halle, M. (1968). The sound pattern of English. New York: Harper \& Row.

Dolinsky, R. (1973). Word fragments as recall cues: Role of syllables. Journal of Experimental Psychology, 97, 272-274.

HANSEN, D., \& RodGers, T. S. (1965). An exploration of psycholinguistic units in initial reading. Proceedings of the Symposium on the Psycholinguistic Nature of the Reading Process. Detroit: Wayne State University.

Horowitz, L. M., White, M. A., \& Atwood, D. W. (1968). Word fragments as an aid to recall: The organization of a word. Journal of Experimental Psychology, 76, 219-226.

KAHN, D. (1976). Syllable-based generalization in English phonology. Doctoral dissertation, Massachussets Institute of Technology, Boston. Reproduced by the Indiana University Linguistic Club.

KAY, J., \& MARCEL, A. (1981). One process, not two, in reading aloud:
Lexical analogies do the work of non-lexical rules. Quarterly Journal of Experimental Psychology, 33A, 397-413.

KuČERA, H., \& Francis, W. N. (1967). Computational analysis of present-day American English. Providence, RI: Brown University Press.

Lima, S. D., \& Pollatsek, A. (1983). The Basic Orthographic Syllabic Structure (BOSS) reconsidered: Lexical access via an orthographic code? Journal of Verbal Learning \& Verbal Behavior, 22 , 310-322.

MARCEL, A. J. (1980). Surface dyslexia and beginning reading: A revised hypothesis of the pronunciation of print and its impairments. In M. Coltheart, K. Patterson, \& J. C. Marshall (Eds.), Deep dyslexia. London: Routledge \& Kegan Paul.

MCClelland, J. L., \& Rumelhart, D. E. (1981). An interactive activation model of context effects in letter perception: Part 1. An account of basic findings. Psychological Review, 88, 375-407.

Mehler, J., Dommergues, J. Y., Frauenfelder, U., \& Segui, J. (1981). The syllable's role in speech segmentation. Journal of Verbal Learning \& Verbal Behavior, 20, 298-305.

MurRell, G. A., \& Morton, J. (1974). Word recognition and morphemic structure. Joumal of Experimental Psychology, 102, 963-968.

Prinzmetal, W., Treiman, R., \& Rho, S. H. (1986). How to see a reading unit. Journal of Memory \& Language, 25, 461-475.

SEgul, J. (1984). The syllable: A basic perceptual unit in speech processing? In H. Bouma \& D. G. Bouwhuis (Eds.), Attention and performance X: Control of language processes. Hillsdale, NJ: Erlbaum.

SPOEHR, K. T. (1978). Phonological recoding in visual word recognition. Journal of Verbal Learning \& Verbal Behavior, 17, 127-141.

SpoenR, K. T. , \& SмITH, E. E. (1973). The role of syllables in perceptual processing. Cognitive Psychology, 5, 71-89.

SpoenR, K. T., \& Sith, E. E. (1975). The role of orthographic and phonotactic rules in perceiving letter patterns. Journal of Experimental Psychology: Human Perception \& Performance, 1, 21-34.

TAFT, M. (1979). Lexical access via an orthographic code: The Basic Orthographic Syllabic Structure (BOSS). Journal of Verbal Learning \& Verbal Behavior, 18, 21-39.

TAFT, M., \& ForSTER, K. I. (1975). Lexical storage and retrieval of prefixed words. Journal of Verbal Learning \& Verbal Behavior, 14, 638-647.

UNDERWOOD, B. J., \& SCHULz, R. W. (1960). Meaningfulness and verbal learning. Chicago: Lippincott.

Webster's new world dictionary of the American language. (1964). New York: World.

\section{NOTE}

1. By "unpronounceable clusters," we mean clusters that are phonotactically irregular in English.

\section{APPENDIX \\ Stimuli Used in Experiments 1 and 2}

Stimuli Used in Experiment 1

\begin{tabular}{|c|c|c|c|c|c|}
\hline Synonym & Syllable & $\begin{array}{l}\text { Pronounc. } \\
\text { nonsyllab. }\end{array}$ & $\begin{array}{l}\text { Unpron. } \\
\text { cluster }\end{array}$ & $\begin{array}{l}\text { Nonadj. } \\
\text { letters }\end{array}$ & Target \\
\hline $\begin{array}{l}\text { liquid metal } \\
\text { uninhabited }\end{array}$ & MER & ERC & $\mathrm{RCU}_{--}$ & M_R_U & MERCURY \\
\hline place & WIL & ILD & -.LDE & W_-_E_N__- & WILDERNESS \\
\hline unpaid worker & VOL & _.LUN & -_NTE_. & $\mathbf{V}_{--} \mathbf{U}_{-} \mathbf{T}_{---}$ & VOLUNTEER \\
\hline pierce & PEN & _NET & ETR_-- & P_N___A & PENETRATE \\
\hline enchant & CAP & _-_TIV & _.PTI & C__T__A & CAPTIVATE \\
\hline roast & BAR & -_BEC_- & $\mathbf{R B E}_{-}$ & B_R_E_- & BARBECUE \\
\hline careless & NEG & _LIG & _EGL & $\mathrm{N}_{-\_} \mathrm{L}_{--} \mathrm{E}_{--}$ & NEGLIGENT \\
\hline move around & CIR & CUL & -_RCU & C.R $\mathbf{A}_{--}$ & CIRCULATE \\
\hline invent & FAB & ...RIC_..- & ABR & F_.R__A & FABRICATE \\
\hline agreement & HAR & MON & _RMO_. & H_R_O.. & HARMONY \\
\hline true & FAC & ACT & $\mathrm{CTU}_{--}$ & F_C_U & FACTUAL \\
\hline
\end{tabular}


APPENDIX (Continued)

\begin{tabular}{|c|c|c|c|c|c|}
\hline Synonym & Syllable & $\begin{array}{l}\text { Pronounc. } \\
\text { nonsyllab. }\end{array}$ & $\begin{array}{l}\text { Unpron. } \\
\text { cluster }\end{array}$ & $\begin{array}{l}\text { Nonadj. } \\
\text { letters }\end{array}$ & Target \\
\hline enlarge & $\mathrm{MAG}_{-\ldots}$ & --_NIF & SGN & M_G I & MAGNIFY \\
\hline copy & ${ }_{2} P_{1}$ & DUP & _UPL & P_I_-T & DUPLICATE \\
\hline disgust & _-VUL _... & $\mathrm{REV}$ & $\ldots$ LSI_- & --V_L_II - & REVULSION \\
\hline aspect & --MEN & DIM & $\ldots$ NSI_. & ${ }_{--} M_{-} N_{-} I_{--}$ & DIMENSION \\
\hline protective & FEN & DEF & $\mathrm{NSI}_{--}$ & F_N_I & DEFENSIVE \\
\hline unwilling & ${ }_{-} \mathrm{LUC}_{---}$ & $\mathrm{REL}$ & CTA & ${ }_{-} L_{-} C_{-} A_{--}$ & RELUCTANT \\
\hline unbiased & _-PAR_--- & IMP & MPA & --P_R_I_- & IMPARTIAL \\
\hline leavetaking & _PAR & DEP & $\ldots \mathrm{RTU}_{--}$ & ${ }_{--} P_{-} R_{-} U_{--}$ & DEPARTURE \\
\hline anusement & _-VER & DIV & RSI & ${ }_{--} V_{-} R_{-} I_{--}$ & DIVERSION \\
\hline loathsome & __PUL & REP & _..._LSI_- & _.P_L_I_- & REPULSIVE \\
\hline resentful & $\ldots \mathrm{DIG}$ & IND & NDI & _D_G_A & INDIGNANT \\
\hline choosy & _.LEC & SEL & $\mathrm{CTI}_{--}$ & ${ }_{--} L_{-} C_{-} I_{--}$ & SELECTIVE \\
\hline $\begin{array}{l}\text { lonely state } \\
\text { irresistible }\end{array}$ & _.CLU & SEC & $\mathrm{ECL}_{-}$ & E_L_S & SECLUSION \\
\hline force & _-_PUL & _OMP & --MPU & O_P_S & COMPULSION \\
\hline continual & SIS $_{---}$ & ERS & ..RSI & $\mathrm{RI}_{\mathrm{T}}$ & PERSISTENT \\
\hline confused & WIL & ILD & _._-LDE_-- & W_L_E_E & BEWILDERED \\
\hline forecast & --_DIC:-- & _RED & ..... CIL & ...D_C_I & PREDICTION \\
\hline thorough & --TEN & $\ldots E_{n}$ & ....NSI_- & .-T_N_I-- & INTENSIVE \\
\hline \multicolumn{6}{|l|}{ crowded } \\
\hline condition & GES & $\mathrm{ONG}_{-}$ & $\mathrm{NGE}_{\ldots}$ & O_G_S & CONGESTION \\
\hline not wanted & WEL & ELC & $\mathrm{LCO}_{--}$ & --W_L_O_- & UNWELCOME \\
\hline spiteful & ...DIV & ICT & ${ }_{--} \mathrm{NDI}_{-}$ & ${ }_{--N} N_{-} T_{-2}$ & VINDICTIVE \\
\hline friend & --_PAN & _OMP & MPA & O.P.N & COMPANION \\
\hline repay & ---PEN & _...ENS & $\mathrm{MPE}_{-}$ & O.P_N & COMPENSATE \\
\hline stamina & _-DUR_--- & $\mathrm{RAN}_{-}$ & NDU & D_A_C_ & ENDURANCE \\
\hline excellence & FEC & $\mathrm{ECT}_{2}$ & RFE & ....F_C_I & PERFECTION \\
\hline liurdle & C:LE & _. TAC -_ & $A C L_{-}$ & $B_{-}$C EE & OBSTACLE \\
\hline increase & PLY & _ULT & $\ldots$....IPL_ & $L_{--} P_{-} Y$ & MULTIPLY \\
\hline retaliation & - SAL & _._RIS_- & EPR & $\mathrm{P}_{-} \mathrm{I}_{-} \mathrm{L}$ & REPRISAL \\
\hline upright & $\mathrm{CAL}$ & ERT $_{-}$ & RTI & E.T L L & VERTICAL \\
\hline unique & ----LAR & --_GUL & ._NGU_... & I_G & SINGULAR \\
\hline \multicolumn{6}{|l|}{ international } \\
\hline negotiator & MAT & _-_LOM_- & _IPL & ${ }_{-} \mathrm{P} \_\mathrm{O} \_\mathrm{T}$ & DIPLOMAT \\
\hline reference book & $\ldots \mathrm{NAC}$ & --MAN -- & $\mathrm{LMA}_{-}$ & ${ }_{-} \mathrm{L}_{-} \mathrm{A}_{--} \mathrm{C}$ & ALMANAC \\
\hline watchman & -NEL & -_-TIN _- & $\mathrm{NTI}$ & ${ }_{-} \mathrm{N} \_\mathrm{I} \ldots \mathrm{L}$ & SENTINEL \\
\hline \multicolumn{6}{|l|}{ buttoned } \\
\hline sweater & GAN & $\ldots D_{\text {DIG }}$ & _-RDI _-- & A.D & CARDIGAN \\
\hline cruel & MAN & _-HUM -- & -NHU & $\mathrm{N}_{-} \mathrm{U}_{-} \mathrm{N}$ & INHUMAN \\
\hline biased & SAN & -..'TIS_- & _.RTI & $\ldots \mathrm{R} \perp \ldots \mathrm{N}$ & PARTISAN \\
\hline deviant & MAL & ORM & RMA & O_M $-\mathrm{L}$ & ABNORMAL \\
\hline
\end{tabular}

Stimuli Used in Experiment 2

\begin{tabular}{|c|c|c|c|}
\hline Synonym & Phonetic unit & Morphemic unit & Target \\
\hline not pertinent & -_REL & $\mathrm{LEV}_{\ldots}$ & IRRELEVENT \\
\hline $\begin{array}{l}\text { disrespectful } \\
\text { manage skillfully; }\end{array}$ & REV & $\ldots$.... VER _-- & IRREVERENT \\
\hline control & --NIP & PUL ... & MANIPULATE \\
\hline boring; dull & NOT & TON _.. & MONOTONOUS \\
\hline meat-eating & ${ }_{---} \mathrm{NIV}$ & _..._VOR_-. & C:ARNIVOROUS \\
\hline $\begin{array}{l}\text { grow or spread } \\
\text { rapidly } \\
\text { exclusive control }\end{array}$ & $\ldots \mathrm{LIF}_{-----}$ & $\mathrm{FER}_{\ldots}$ & PROLIFERATE \\
\hline $\begin{array}{l}\text { or ownership } \\
\text { disloyalty; }\end{array}$ & _-NOP & POL_ & MONOPOLY \\
\hline $\begin{array}{l}\text { unfaithfulness } \\
\text { component structure; }\end{array}$ & $\ldots$.... DEL & FID & INFIDELITY \\
\hline dissection & NAT & _... TOM_ & ANATOMY \\
\hline all-powerful & _-NIP & _POT__- & OMNIPOTENT \\
\hline splendid & $\ldots N I F$ & $\ldots \mathrm{FIC}_{-}$ & MAGNIFICENT \\
\hline
\end{tabular}


APPENDIX (Continued)

\begin{tabular}{|c|c|c|c|}
\hline Synonym & Phonetic unit & Morphemic unit & Target \\
\hline tighttly joined & _SEP & _-_PAR_-_ & INSEPARABLE \\
\hline equipment & $\ldots$ RAT $_{--}$ & PAR & APPARATUS \\
\hline look forward to & _-TIC & _._.'IP & ANTICIPATE \\
\hline independence & _-TON_.. & $\mathrm{NOM}_{-}$ & AUTONOMY \\
\hline $\begin{array}{l}\text { kind; generous } \\
\text { hesitant; unable }\end{array}$ & -.NEV & .....VOL_-- & BENEVOLENT \\
\hline to decide & RES & SOL_... & IRRESOLUTE \\
\hline vague; not exact & _.DEF & _._FIN__- & INDEFINITE \\
\hline $\begin{array}{l}\text { mix uniformly } \\
\text { vigorous; full }\end{array}$ & --MOG & $\ldots \mathrm{GEN}_{-}$ & HOMOGENIZE \\
\hline of pep & GET & ERG & ENERGETIC \\
\hline conflicting feelings & _.BIV & -..-VAL_... & AMBIVALENCE \\
\hline $\begin{array}{l}\text { secret; not to be } \\
\text { disclosed } \\
\text { applied science } \\
\text { unlawful }\end{array}$ & $\begin{array}{l}\text { DEN } \\
\ldots \text { NOL } \\
\ldots \text { GIT }\end{array}$ & $\begin{array}{l}\mathrm{FID}_{-} \\
\mathrm{L} \mathrm{LOG}_{-} \\
\mathrm{LEG}\end{array}$ & $\begin{array}{l}\text { CONFIDENTIAL } \\
\text { TECHNOLOGY } \\
\text { ILLEGITIMATE }\end{array}$ \\
\hline
\end{tabular}

(Manuscript received March 6, 1987 ;

revision accepted for publication September 11, 1987.) 